\title{
Peer Support as a Mediator between Bullying Victimization and Depression
}

\author{
Chenguang $\mathrm{Du}^{1}$, Kara DeGuisto ${ }^{2}$, Jordan Albright ${ }^{3} \&$ Sara Alrehaili ${ }^{1}$ \\ ${ }^{1}$ School of Education, Virginia Polytechnic Institute and State University, Blacksburg, United State, USA \\ ${ }^{2}$ Department of Population Health Sciences, Virginia Polytechnic Institute and State University, USA \\ ${ }^{3}$ Department of Psychology, Virginia Polytechnic Institute and State University, USA \\ Correspondence: Chenguang Du, School of Education, Virginia Polytechnic Institute and State University, \\ Blacksburg, United State.
}

Received: January 19, 2018

Accepted: February 11, 2018

Online Published: February 21, 2018

doi:10.5539/ijps.v10n1p59

URL: http://doi.org/10.5539/ijps.v10n1p59

\begin{abstract}
Bullying has been one of the most common forms of school violence in the world. Many studies have shown that victims of bullying suffer from serious psychological issues. In the current study, the relationships between three variables: bullied victim, peer support, and depression symptom were assessed, using published data from the 2009-2010 Health Behavior in School-Aged Children Survey $(N=12,642)$. The data was collected from 314 public, Catholic, and other private schools in the United States that enrolled students from grades 5, 6, 7, 8, 9 , and 10 or their equivalent in 50 states and the District of Columbia. The results indicated: (1) bullied victim was positively associated with depression symptom, with higher victimization score reporting higher depression symptoms; (2) bullied victim was negatively associated with peer support, with higher victimization score reporting lower peer support; (3) peer support was negatively related to depression symptoms; and (4) peer support partially mediates the relationship between victimization and depression symptoms among bullied students. This empirical study underscores the important role of peer support in mitigating the negative effects of bullying on the victim's depression symptoms, which also provide empirical support for intervention programs based on the peer support system.
\end{abstract}

Keywords: bullying, victimization, peer support, depression symptom

\section{Introduction}

More than $21 \%$ of American students reported being bullied (Finkelhor, Turner, Shattuck \& Hamby, 2015) and most of them reported having suffered adverse consequences, such as loneliness, low self-esteem and depression symptoms (Holt et al.,2015; Milsom \& Gallo, 2006; Uba, Yaacob \& Juhari, 2010; Wang, Iannotti, \& Nansel, 2009). In school prevention and well-being research, peer support has received considerable attention because it was related to both bullied victims and depression and was effective in mitigating the related depression symptom. Specifically, many studies have indicated that bullied victims were positively associated with depressed symptoms and negatively associated with peer support at school (Holt \& Espelage, 2007; Kaltiala-Heino \& Fröjd, 2011; Perren \& Hornung, 2005; Milsom \& Gallo, 2006;). However, the mechanism of how peer support influences the relationship between bullied victims and depression is less understood. Building upon the buffering hypothesis of social support, the current study investigated the mediation role of peer support in the relationship between the bullied victims and depression symptoms.

\section{Literature Review}

School bullying is one of the most common forms of violence over the last 30 years in the United States. According to the statistics from NCES, in 2013, at least 22 percent of 12-18 year old students reported being bullied during the school year. Among these students aged 12-18, around 14 percent reported that they were made fun of, called names, or insulted; 13 percent reported being the subject of rumors; and 6 percent reported that they were pushed, shoved, tripped, or spit on (U.S. Department of Education, National Center for Education Statistics. (2017). Indicators of School Crime and Safety: 2016 (NCES 2017-064). Retrieved from https://nces.ed.gov/fastfacts/). "A recent meta-analysis of 80 studies that reported rates for traditional and cyber-perpetration, victimization, or both, revealed a mean prevalence rate among school-aged youth of $35 \%$ for 
traditional bullying involvement and $15 \%$ for cyberbullying involvement" (Modecki, Minchin, Harbaugh, Guerra, \& Runions, 2014).

There is an emerging consensus among scholars that bullying is conceptualized or defined as repeated aggressive acts against a specific target, such as students who cannot easily defend him- or herself. According to Olweus and Limber (2010), "Bullying is a subset of aggression or aggressive behavior [...] with certain special characteristics such as repetitiveness and an asymmetric power relationship." Therefore, the premise of bullying is "a violent behavior between the victims and the perpetrators who seek to control or power over others" (Rettew \& Pawlowski, 2016). In addition, Salmivalli and colleagues (1999) have suggested that the bullying phenomenon can also be understood under the context of social relations and group dynamics, as bullying does not always concern only a single victim and bully. The other pupils present may either support the perpetrators by their behaviors, try to defend the victim, or withdraw.

Many cross-sectional studies found that being the victim of school bullying is positively associated with self-reported depression symptoms. (Arseneault, Bowes, \& Shakoor, 2010; Ledwell \& King, 2015; Uba, Yaacob \& Juhari, 2010). For example, Fleming and Jacobsen (2009) conducted a study to examine the relationship between reports of bully victimization and depression symptoms among middle schoolers in Chile. Results from the study indicated that students who were bullied in the past month were more likely than non-bullied students to report symptoms of depression and were less likely to report having peer support. Klomek et al. (2007) also studied the relationship between bullying behavior and depression among a large sample of high schoolers in Nassau, Suffolk, and Westchester counties in New York. The results suggested that students who were frequently bullied in or away from schools were seven times more likely to be depressed than students who never got bullied. Even for students who were infrequently bullied in or away from school, the risk of being depressed was one or two times higher than non-bullied students.

In some longitudinal follow-up studies the bullying victim illustrated depressive symptom in the short-term and also in the long-term. A study conducted by Haavisto and colleagues (2004) found that Finnish boys who were bullied at age 8 in school reported having more depressive symptoms in late adolescence. Similarly, Takizawa, Maughan and Arseneault (2014) conducted ordinal logistic regression analyses on data collected from 7,771 participants whose parents reported bullying exposure at ages 7 and 11 years, with follow-up assessments between ages 23 and 50 years. Their results indicated that victims of frequent bullying in childhood had an increased risk of developing both depression and anxiety disorders at age 45. This was also true for children who were occasionally bullied, as the risk of depression was also increased in their adult life. In sum, empirical studies have confirmed that being the victim of bullying will increase the risk of depression indefinitely.

Apart from developing symptoms of depression, bullied victims also receive less peer support than those who are not bullied at school. The peer nomination study first revealed how bullies and victims were perceived differently by other peers (Boulton \& Smith, 1994). The bullies were often nominated as the most aggressive and disruptive children, while the victims were often perceived as being the most needy by repeatedly seeking help from others, which implied a lack of confidence or self-esteem and marked them as the bullied targets at school. In a longitudinal study, Smith et al. (2004) investigated why some children were bullied, while others escaped. They found that compared to these "escaped victims," the "continuous victims" had significantly worse school attendance rates. This lower school attendance isolated them further from their peers and undermined a healthy relationship between continuous victims and their peers. Champion, Vernberg, and Shipman (2003) also assessed friendship characteristics and social skills between bullied and non-bullied students in a single junior high school. Their results indicated that bullied students often received less peer support than the non-bullied students because they often had difficulties in managing the interpersonal confrontation under the peer interaction. It is also very important to note that having less peer support does not necessarily indicate having fewer friends. Occasionally, the individual being bullied had a lower quality of friendships but abundance in number of friends at school. For instance, victims may have limited skills to solve the disagreement or conflict efficiently with their friends or put less effort into assisting each other with routine challenging tasks. In addition, the frequency of conflict or betrayal among friends was also associated with the perception and satisfaction of peer support (Holt \& Espelage, 2007).

The ecological framework (Bronfenbrenner \& Morris, 2006) proposes that the microsystem, which consists of individuals or groups within the immediate settings where students have face to face interactions, has the most direct impact on school bullying. Therefore, as suggested by Hong and Espelage (2012), the microsystem level analysis of school bullying behavior needs to consider peer relationship or peer support. Previous studies indicated that peer support could function as a protective factor to promote psychological well-being of school students under adverse conditions (Noltemeyer \& Bush, 2013). For example, in the developmental transition 
from early to middle adolescence, the peer support could be a protective factor diminishing the magnitude of depressive symptoms among white youth (Vaughan, Foshee, \& Ennett, 2010). Matlin, Molock, and Tebes (2011) administered surveys to several schools in the Washington, D.C. area to examine the risk and protective factors of suicide rates in African American adolescents. Their results supported that the elevated peer support could mitigate suicide rate and depression symptom for African American adolescents. In modern times, peer support under cyberspace or virtual environment could play the same role as it is in the real environment. According to Setoyama, Yamazaki, and Namayama (2011), peer support provided by an online community was particularly beneficial to cancer patients in Japan for overcoming the depression and anxiety related to their prognosis. To date, after realizing the advantage of peer support in inhibiting the negative effects of bullying behaviors, many schools try to implement intervention programs based on the peer support to maintain or improve student's emotional health or wellbeing, especially for the bullied victims (Cowie, 2014). These programs emphasize that pupils themselves also have the potential to assume a helpful role in cracking down the detrimental effects on bullying (Cowie \& Olafsson, 2000; Peterson \& Rigby, 1999). For example, some secondary schools in the United State offered peer mentors who worked as mediators to resolve interpersonal conflicts among students through a structured process.

Overall, the literature supports that school bullying is still a prevalent social issue in the United States, and that peer support can be used as a protective resource to mitigate negative outcomes brought on by bullying behaviors (Kaltiala \& Fröjd, 2011). Little research has explicitly examined the relationship between peer support and depressive symptoms among bullied students. According to the buffering model, peer support may minimize the stress caused by victimization and depression by attenuating the stress appraisal response (Cohen \& Wills, 1985). The perception that peers will provide helpful resources may redefine the potential harm brought on by a bullied experience. This bolsters one's perceived ability to cope with bullied experience and therefore prevents this experience being appraised as highly stressful. As such, we hypothesized that peer support could mediate the relationship between the bullied victim and depression symptoms. Well-documented depression symptoms among bullied victims could potentially be mediated by how much peer support they have at school. In conclusion, this will help researchers better understand the mechanism of how peer support is related to the bullied victims, and also provide empirical support for the buffering effects played by peer support on the psychological wellbeing.

\section{Method}

\subsection{Sample and Data}

The World Health Organization (WHO) conducted a school-based, cross-sectional survey titled "Health Behavior in School-Aged Children (HBSC)," which was a collected over 30 countries to monitor youth health-risk behaviors and attitudes. The current study used HBSC 2009-2010 school data for the U.S. from the 2009-2010 school year. The sample included 12,642 students from 314 public, Catholic, and other private schools who were enrolled in grades 5, 6, 7, 8, 9, and 10 or their equivalent in the United States. In most schools in the U.S., education is divided into three levels: elementary school (kindergarten to 5th grade), middle school (grades 6th to 8th), and high school (grades 9th to 12th). HBSC 2009-2010 data are maintained and distributed to the general public free of charge (upon registration and agreement with the terms of use) by the Inter-university Consortium for Political and Social Research. HBSC objectives include monitoring health-risk behaviors of adolescents, examining extensive information on substance use (e.g., tobacco, alcohol, and marijuana), and various health behaviors and attitudes (including video gaming, eating habits, physical activity, body image, health problems). The demographic and socio-economic statuses of the students' family were also examined. Students were asked about their relationship with their parents and the level of parental control over their activities. These questions were used for creating instrumental variables, which are used to help identify the social support.

\subsection{Measurement}

Socio-demographic variables. Socio-demographic variables consist of gender, age, race (White, American Indian or Alaska Native, Native Hawaiian or Other Pacific Islander, Black or African-American, Asians, Hispanic, and Two or More Races) and family affluence. Family socioeconomic status was evaluated with the Family Affluence Scale (FAS): adolescent having his/her own bedroom, frequency of family traveling vacations, and the number of family computers and motor vehicles (Iannotti \& Wang, 2013). The FAS is a continuous scale ranging from 1 to 9 , with higher numbers relating to higher social economic status.

Victimization (bullied victim). In Jeong and Lee (2013), 11 items were composited to measure both physical and emotional victimization. For example, students were asked "how often got bullied: left out of things", "how 
often got bullied: hit / kicked / pushed", "how often got bullied: for my race / color", and "how often got bullied: others lied about me." These global items were arranged along a five-point, relative frequency-based response scale (i.e., $1=\mathrm{I}$ haven't been bullied at school the past couple of months, 2 = It has only happened once or twice, $3=2$ or 3 times a month, $4=$ About once a week, $5=$ Several times a week). The Cronbach's alpha of the current scale is .899 .

Peer support. Peer support is measured by asking individuals to rate their response to three items, which include: My class enjoy being together; My class are kind and helpful; and My class accept me as I am (Jeong \& Lee, 2013). Responses were recorded using a five-point Likert scale from 1 (strongly disagree) to 5 (strongly agree). The data was collapsed into new continuous variables with a higher mean score indicating more warmth and support from peers. The Cronbach's alpha is equal to 0.730 in this study.

Depression symptom. In Iannotti and Wang's research (2013), the measure of depression symptomology was illustrated by having participants indicate how often in the past 30 days they: (1) feel low; (2) were grouchy or irritable; (3) feel nervous; (4) feel difficulty in sleep; (5) felt hopeless about the future. Responses were coded from one to five: "never," "seldom," "sometimes," "often" and "always," with higher mean score indicating greater depressive symptomology. The Cronbach's alpha for this measure is 0.711 in the current study.

\section{Statistical Methods}

First, descriptive statistics was employed to create a demographic profile including gender, age, grade, race and family socioeconomic status in the study sample. Second, the Pearson correlation analysis was used to assess the strength of association among the interested variables (i.e. peer support, victimization, and depression symptom). Third, in order to test the mediation effect of peer support, four steps were conducted of multiple regression analyses proposed by Hayes (2017).

\section{Results}

\subsection{Demographic Information}

Table 1 illustrates the descriptive statistics for the socio-demographic variables. The present sample consisted of 6,502 males $(51.4 \%)$ and 6,136 females $(48.6 \%)$, which are very similar in their population proportion. The mean school grade was 7.54 (S.D.=1.75), with range distribution from grade 5 to grade 10 (grade $5=13.6 \%$, grade $6=16.2 \%$, grade $7=19.2 \%$, grade $8=19.6 \%$, grade $9=16.4 \%$, and grade $10=15.1 \%$ ). The chi-square test shows that the grade is not equally distributed in our sample, $\chi 2(5, \mathrm{~N}=12642)=204.364, \mathrm{p}<0.05$. The distribution of race in current sample is Black or African American $=17.1 \%$, while $=46.7 \%$, Asian $=3.7 \%$, American Indian or Alaska Native $=1.8 \%$, Native Hawaiian or Other Pacific Islander $=0.9 \%$, Two or More Races $=6.5 \%$, Hispanic $=18.9 \%$. The sample also showed that the mean of the Family Influence or SES was 5.91 (middle class), with standard deviation 1.96.

Table 1. Descriptive statistics

\begin{tabular}{lllll}
\hline & $\mathrm{N}(\%)$ & Mean (St. Deviation) & Min. & Max. \\
\hline $\begin{array}{l}\text { Demographic Variables } \\
\text { Gender }\end{array}$ & & & \\
1.Male & $6502(51.4 \%)$ & & 0 & 1 \\
2.Female & $6136(48.6 \%)$ & & 0 & 1 \\
Race & & & & \\
1.White & $5903(46.7 \%)$ & & 0 & 1 \\
2. Asian & $469(3.7 \%)$ & & 0 & 1 \\
3. Hispanic or Latino & $2392(18.9 \%)$ & & 0 & 1 \\
4. Black or African American & $2164(17.1 \%)$ & & 0 & 1 \\
5.American Indian or Alaska Native & $222(1.8 \%)$ & & 0 & 1 \\
6. Native Hawaiian or Other Pacific Islander & $111(0.9 \%)$ & & 0 & 1 \\
Two or More Races & $828(6.5 \%)$ & & 0 & 1 \\
Age (mean) & & $12.95(1.75)$ & 10 & 17 \\
Grade in School (mean) & & $7.54(1.61)$ & 5 & 10 \\
Family Affluence Scale(SES) & & $5.91(1.96)$ & 0 & 9 \\
Bullied Victim & & $1.34(0.62)$ & 1 & 5 \\
Peer Support & & $3.02(2.86)$ & 1 & 5 \\
Depression Symptom & & & 1 & 5 \\
\hline
\end{tabular}




\subsection{Correlation Analysis Results}

As shown in Table 2, the Pearson correlation indicated that most interesting variables were significantly correlated with each other. First, peer support had a significant and negative correlation with the depression symptom $(r(12215)=-.081, p<0.05)$. Second, it was also observed that peer support had a significantly negative correlation with victimization $(r(12220)=-.186, p<0.05)$. Finally, bullied victimization was significantly positively related to depression symptoms $(r(11944)=.250, p<0.05)$.

Table 2. Correlation among interested variables

\begin{tabular}{lllllll}
\hline & Age & Gender & SES & Peer Support & Victim & Depression \\
\hline Age & 1 & & & & & \\
Gender & $-.038^{* * *}$ & 1 & & & & \\
SES & $-.033^{* * *}$ & .010 & 1 & & & \\
Peer & $.063 * * *$ & $.038^{* * *}$ & $.067^{* * *}$ & 1 & & \\
Support & $.063^{* * *}$ & & & & \\
Victim & $-.060^{* * *}$ & -.011 & $-.032^{* *}$ & $-.186^{* * *}$ & 1 & \\
Depression & $.104^{* * *}$ & $.162^{* * *}$ & $-.055^{* * *}$ & $-.081^{* * *}$ & $.250^{* * *}$ & 1 \\
\hline Note. $* * *$ Significant at the 0.01 level (2-tailed) $)^{* *}$ significant at the 0.05 level (2-tailed) &
\end{tabular}

Note. ${ }^{* * *}$ Significant at the 0.01 level (2-tailed), ${ }^{* *}$ significant at the 0.05 level (2-tailed).

\subsection{Mediation model Analysis Results}

The results of the mediation model analysis can be found in Table 3. The SPSS version 18.0 with Process macro was used to test the hypothesized mediation model (Hayes, 2017). The first step was to examine the direct effect of victimization on depression, where the dependent variable (depression symptoms) was regressed on the independent variable (victimization) while controlling for gender, age and SES. There was a positive association between these variables $\left(\beta=.440, t=21.785, p<0.05, R^{2}=0.107\right)$, such that individuals who experienced higher rates of bullying reported higher levels of depression. These results correspond to Path c in Figure 1 . The $R^{2}$ here indicated that $10.7 \%$ of the variance in depression was explained by bullied victimization, gender, age and SES.

The second step of analysis was to assess whether victimization could predict peer support, where the independent variable (victimization) was regressed on the mediator (peer support) by controlling gender, age and SES. As expected, there was a negative relationship between the two variables $(\beta=-.559, t=-13.011, p<0.05$, $R^{2}=.0371$ ), such that teenagers who were victims of bullying reported lower levels of peer support. Similarly, The $R^{2}$ indicated that at least $3.7 \%$ of the variance in peer support could be explained by victimization, gender, age and SES together. These results correspond to Path a in Figure 2.

In the third step, the dependent variable (depression symptoms) was regressed simultaneously on both the mediator (peer support) and the independent variable (victimization), while controlling for age, gender and SES. This resulted in the following unstandardized regression coefficients for path $\mathrm{b}(\beta=-.037, t=-5.835, p<0.05)$ and $c^{\prime}(\beta=.419, t=20.536, p<0.05)$, respectively in Figure 2 . When victimization and peer support were combined as independent variables to predicate the depression symptoms, the impact of victimization on depression (indirect effect) became weaker, with the regression coefficient dropping from 0.440 to 0.419 , whereas the indirect impact of victimization on depression was still significant $(\beta=.419, t=20.536, p<0.05)$. The bootstrap confidential interval for this indirect effect is $(0.014,0.028)$, which does not contain 0 , meaning that the indirect effect is valid in our analysis. The Sobel-Test (Sobel, 1987) was also calculated to confirm that this mediation effect is actually significant $(t=6.955, p<0.01)$. In conclusion, these findings suggest that peer support partially mediates the relationship between victimization and depression. 
Table 3. Mediation effect of peer support among victim and depression symptoms

\begin{tabular}{lllll}
\hline & $\beta$ & $\mathrm{t}$ & $\mathrm{R}$ & $\mathrm{F}$ \\
\hline Model1 (Depression) & .360 & $19.556^{* * *}$ & .107 & \\
Gender & .0763 & $14.275^{* * *}$ & & \\
Age & -.023 & $-4.689^{* * *}$ & & \\
SES & .440 & $21.785^{* * *}$ & & \\
Bullied Victim & & & .0371 & \\
Model 2 (Peer Support) & .010 & $0.297^{* * *}$ & & \\
Gender & .015 & $1.380^{* * *}$ & \\
Age & .037 & $4.483^{* * *}$ & & \\
SES & -.559 & $-13.011^{* * *}$ & & \\
Bullied Victim & & & .333 & \\
Model 3 (Depression) & .361 & $19.614^{* * *}$ & & \\
Gender & -.022 & $-4.421^{* * *}$ & & \\
SES & .077 & $14.390^{* * *}$ & & \\
Age & .419 & $20.536^{* * *}$ & & \\
Bullied Victim & -.037 & $-5.835^{* * *}$ & & \\
Peer Support & & & \\
\hline
\end{tabular}

Note. ${ }^{* * *}$ Correlation is significant at the 0.01 level (2-tailed).

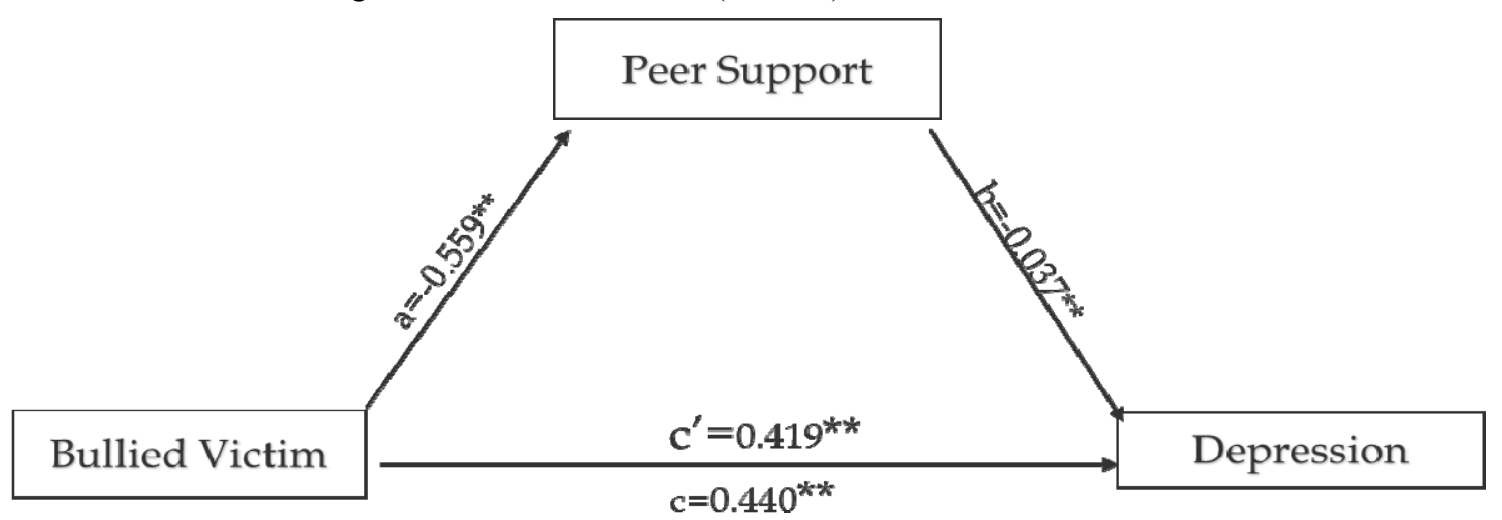

Figure 1. Peer support mediates the relationship between bullied victim and depression symptoms

\section{Discussion}

Results from the current study confirmed that there is a positive relationship between bullying victimization and depression symptoms. Higher prevalence of bullying victimization, the higher depression levels reported among teenagers in this sample. These findings are consistent findings from the literature which suggest that depression symptoms, such as sadness and hopelessness, are significantly increased among those who have been bullied at school (Mill et al., 2004; Wang, Iannotti \& Nansel, 2009). One possible reason for consistent higher rates of depression among bullied victims may be related to the excessive activation of the stress system center on hypothalamic-pituitary-adrenal (HPA) axis (Rhebergen et al., 2015). Being bullied is a major stressful life event for school students. Prolonged exposure to stressful events could make HPA and other stress hormone systems become hypo-functional. As suggested by Barra et al. (2015), this diminished function may break down the circadian or daily rhythm of cortisol, which could further cause a profound interruption in sleeping patterns, such as difficulties awaking in the morning or falling asleep at night. Evidence from developmental psychopathology studies supported a positive association between the sleep deficits and somatic or internalizing symptoms such as headache, chronic pain, less emotional regulation, mood disorder, anxiety and depression (Harvey \& Tang, 2012; Jovanovic et al., 2011; Kidger et al., 2015).

Our analysis also confirmed that the victimization is negatively correlated with peer support. This finding is also 
consistent with previous from the literature. For example, Flaspohler et al. (2009) investigated the impact of bullying on the school student's quality of life, using a large sample of elementary and middle school children. The results indicated that bullied students always experienced reduced life satisfaction and peer support compared to bystanders (children who are neither victims nor perpetrators of bullying). Cowie and Hutson (2005) found that these continuously bullied victims had a worse attendance rate at school, isolating them further from their peers. One possible reason explanation for this negative relationship between victimization and peer support is that those who are often bullied at school also have low self-esteem and poor social skills, which may pre-date victimization and may well affect how successful the individual is in taking steps to escape for the bullying. Presumably, being victimized may further damage their self-esteem, thereby perpetuating a cycle and causing these individuals to be more vulnerable to the effects of victimization. Another possible explanation may be that the negative stigma perceived by their peers could hinder the bystanders' willingness to help the victim. Rigby and Slee (1991) found that many children and young people look down on children who are bullied because they are perceived as too "needy" and "demanding." This potential stigma may greatly increase their chance of being rejected by their peers.

The negative correlation between peer support and depression also matched findings by Colarossi (2003) and Domagała-Zyśk (2006). Transitioning from youth to adolescence can be difficult and requires social support from peers. Cowie and Smith (2009) found that peer support not only helps individuals to deal with the emotional impact of rejection and social exclusion at the hands of peers but also creates a more positive ethos in the school community. Sometimes, the peers' response or attitude could make a difference for victims' psychological adjustment. The bullied students who had supportive peers when victimized were found to be less anxious and depressed and have more confidence compared to victims without peer support (Sainio, Veenstra, Huitsing, \& Salmivalli, 2011). In fact, even a mild willingness to listen to or sympathize with the bullied victim from classmate or friends would facilitate their sense of identity and effective regulation of emotions. Unfortunately, most peers just expressed their intention to support the bullied victims in hypothetical conditions and the actual defending behavior reported by their peer reports was rare (Holt \& Espelage, 2007; Pouwelse et al., 2011; Sainio et al., 2011).

The essential hypothesis that peer support mediates the relationship between bullied victims and depression symptoms was also confirmed by the current study. That is, students who were bullied at school receive little peer support, and then suffer the symptoms of depression. This finding not only was fitted to the stress buffer hypothesis that social support mitigates negative outcomes when individual experience the stressful life events, but also extends its application to the bullied victims. In terms of the school environment, peer support network may provide social support in its multiple forms, such as emotional, motivational, instrumental and informational support (Flaspohler et al., 2009). A possible explanation for the mediating role of peer support was summarized by Pouwelse et al. (2011), such that students who are bullied and are noticeably rejected or isolated by their peers may suffer from internalizing problems, lack of adequate social skills to resolve interpersonal conflict, and have lower self-esteem. When they get more peer support, they feel confident and, as a result, report less depression symptomology.

This model also has a meaningful implication for prevention programs aimed at deterring school bullying. The findings of the current study underscored the importance of peer support in reducing the negative effects of bullying and other forms of school violence. Peers might possess social resources, including social support and social capital, which can be mobilized to support bullied victims (Perren \& Hornung, 2005). Schools might also benefit from instituting bullying intervention program that train bystanders with necessary skills to diminish school bullying behaviors. Such a program should help build up a social network which can dynamically prevent the bullying events and reward any classroom change to defend and support the bullied victims. Targeting the bystanders does not mean to leave bullies excluded. In fact, both community and individual interventions are also needed to effectively inhibit bullying behavior.

\section{Conclusions and Limitations}

Our study first confirmed that bullied students reported experiencing several symptoms of depression including, irritableness, lowness, and nervousness. The result also indicated that bullied victims tend to experience less peer support at school. This may be because they lack necessary social skills or are often perceived by their peer groups as too "needy." In addition, the mediating role played by peer support between victimization and depression symptoms was confirmed. This is consistent with the buffering hypothesis of social support, which indicates that the negative impact of stressful life events can be relieved by having a positive social support system in place (Cohen \& McKay, 1984). 
There are also several limitations in our study. The first is that the claims about causal relations among these variables should be made cautiously because the study used cross-sectional data. Future research could consider using the longitudinal study to get sufficient evidence to generate more causal inference for bullied students. Moreover, all the data collected was from the U.S., which may restrict our current finding to other countries. Although, because our findings are consistent with the reviewed literature, the conclusions could still provide some relevance for researchers in other countries. The final limitation concerns the reliability of measurement for the variables of interest. Except for victimization, the internal reliability of peer support and depression symptom was not very high. These measurement scales were from other published articles using the same data set and the relative items were shortened, as the whole questionnaire was considered to be too long for students taking part in the study. Unfortunately, the validity information was not provided for these studies. We therefore recommend future researchers use scales with higher reliability and standardized validity.

\section{References}

Arseneault, L., Bowes, L., \& Shakoor, S. (2009). Bullying victimization in youths and mental health problems: $\begin{array}{lllll} & \text { Much ado about nothing"? Psychological Medicine, 40(05), } 717 .\end{array}$ https://doi.org/10.1017/s0033291709991383

Barra, C. B., Silva, I. N., Rodrigues, T. M. B., Santos, J. L. S., \& Colosimo, E. A. (2015). Morning Serum Basal Cortisol Levels Are Affected by Age and Pubertal Maturation in School-Aged Children and Adolescents. Hormone Research in Paediatrics, 83(1), 55-61. https://doi.org/10.1159/000369801

Boulton, M. J., \& Smith, P. K. (1994). Bully/victim problems in middle - school children: Stability, self perceived competence, peer perceptions and peer acceptance. British journal of developmental psychology, 12(3), 315-329. https://doi.org/10.1111/j.2044-835x.1994.tb00637.x

Bronfenbrenner, U., \& Morris, P. A. (2006). The bioecological model of human development. Handbook of child psychology. https://doi.org/10.1002/9780470147658.chpsy0114

Champion, K., Vernberg, E., \& Shipman, K. (2003). Nonbullying victims of bullies: Aggression, social skills, and friendship characteristics. Journal of Applied Developmental Psychology, 24(5), 535-551. https://doi.org/10.1016/j.appdev.2003.08.003

Cohen, S., \& McKay, G. (1984). Social support, stress and the buffering hypothesis: A theoretical analysis. Handbook of psychology and health, 4, 253-267. https://doi.org/10.1037//0033-2909.98.2.310

Cohen, S., \& Wills, T. A. (1985). Stress, social support, and the buffering hypothesis. Psychological bulletin, 98(2), 310. https://doi.org/10.1037//0033-2909.98.2.310

Colarossi, L. G., \& Eccles, J. S. (2003). Differential effects of support providers on adolescents' mental health. Social Work Research, 27(1), 19-30. https://doi.org/10.1093/swr/27.1.19

Cowie, H., \& Hutson, N. (2005). Peer support: A strategy to help bystanders challenge school bullying. Pastoral Care in Education, 23(2), 40-44. https://doi.org/10.1111/j.0264-3944.2005.00331.x

Cowie, H., \& Olafsson, R. (2000). The role of peer support in helping the victims of bullying in a school with high levels of aggression. School Psychology International, 21(1), 79-95. https://doi.org/10.1177/0143034300211006

Cowie, H., \& Smith, P. K. (2009). Peer support as a means of improving school safety and reducing bullying and violence. In Handbook of prevention science (pp. 177-193). Routledge. https://doi.org/10.4324/9780203866412.ch9

Domagała-Zyśk, E. (2006). The significance of adolescents' relationships with significant others and school failure. School Psychology International, 27(2), 232-247. https://doi.org/10.1177/0143034306064550

Finkelhor, D., Turner, H. A., Shattuck, A., \& Hamby, S. L. (2015). Prevalence of childhood exposure to violence, crime, and abuse: Results from the national survey of children's exposure to violence. JAMA pediatrics, 169(8), 746-754. https://doi.org/10.1001/jamapediatrics.2015.0676

Flaspohler, P. D., Elfstrom, J. L., Vanderzee, K. L., Sink, H. E., \& Birchmeier, Z. (2009). Stand by me: The effects of peer and teacher support in mitigating the impact of bullying on quality of life. Psychology in the Schools, 46(7), 636-649. https://doi.org/10.1002/pits.20404

Fleming, L. C., \& Jacobsen, K. H. (2009). Bullying and symptoms of depression in Chilean middle school students. Journal of school health, 79(3), 130-137.https://doi.org/10.1111/j.1746-1561.2008.0397.x 
Haavisto, A., Sourander, A., Multimäki, P., Parkkola, K., Santalahti, P., Helenius, H., ... \& Aronen, E. (2004). Factors associated with depressive symptoms among 18-year-old boys: a prospective 10-year follow-up study. Journal of Affective Disorders, 83(2), 143-154. https://doi.org/10.1016/j.jad.2004.06.008

Harvey, A. G., \& Tang, N. K. (2012). (Mis) perception of sleep in insomnia: A puzzle and a resolution. Psychological bulletin, 138(1), 77. https://doi.org/10.1037/a0025730

Hayes, A. F. (2017). Introduction to mediation, moderation, and conditional process analysis: A regression-based approach. Guilford Publications.

Holt, M. K., \& Espelage, D. L. (2007). Perceived social support among bullies, victims, and bully-victims. Journal of Youth and Adolescence, 36(8), 984-994. https://doi.org/10.1007/s10964-006-9153-3

Holt, M. K., Vivolo-Kantor, A. M., Polanin, J. R., Holland, K. M., DeGue, S., Matjasko, J. L., ... \& Reid, G. (2015). Bullying and suicidal ideation and behaviors: a meta-analysis. Pediatrics, peds-2014. https://doi.org/10.1542/peds.2014-1864

Hong, J. S., \& Espelage, D. L. (2012). A review of research on bullying and peer victimization in school: An ecological system analysis. Aggression and violent behavior, 17(4), 311-322. https://doi.org/10.1016/j.avb.2012.03.003

Iannotti, R. J., \& Wang, J. (2013). Patterns of physical activity, sedentary behavior, and diet in US adolescents. Journal of Adolescent Health, 53(2), 280-286. https://doi.org/10.1016/j.jadohealth.2013.03.007

Jeong, S., \& Lee, B. H. (2013). A multilevel examination of peer victimization and bullying preventions in schools. Journal of criminology, 2013. 1-10. https://doi.org/10.1155/2013/735397

Jovanovic, T., Smith, A., Kamkwalala, A., Poole, J., Samples, T., Norrholm, S. D., ... \& Bradley, B. (2011). Physiological markers of anxiety are increased in children of abused mothers. Journal of Child Psychology and Psychiatry, 52(8), 844-852.https://doi.org/10.1111/j.1469-7610.2011.02410.x

Kaltiala-Heino, R., \& Fröjd, S. (2011). Correlation between bullying and clinical depression in adolescent patients. Adolescent health, medicine and therapeutics, 2, 37-44. https://doi.org/10.2147/ahmt.s11554

Kidger, J., Heron, J., Leon, D. A., Tilling, K., Lewis, G., \& Gunnell, D. (2015). Self-reported school experience as a predictor of self-harm during adolescence: A prospective cohort study in the South West of England (ALSPAC). Journal of affective disorders, 173, 163-169. https://doi.org/10.1016/j.jad.2014.11.003

Ledwell, M., \& King, V. (2015). Bullying and internalizing problems: Gender differences and the buffering role of parental communication. Journal of family issues, 36(5), 543-566. https://doi.org/10.1177/0192513X13491410

Matlin, S. L., Molock, S. D., \& Tebes, J. K. (2011). Suicidality and depression among African American adolescents: The role of family and peer support and community connectedness. American journal of orthopsychiatry, 81(1), 108-117. https://doi.org/10.1111/j.1939-0025.2010.01078.x

Mills, C., Guerin, S., Lynch, F., Daly, I., \& Fitzpatrick, C. (2004). The relationship between bullying, depression and suicidal thoughts/behaviour in Irish adolescents. Irish Journal of Psychological Medicine, 21(04), 112-116. https://doi.org/10.1017/s0790966700008521

Milsom, A., \& Gallo, L. L. (2006). Bullying in middle schools: Prevention and intervention. Middle School Journal, 37(3), 12-19. https://doi.org/10.1080/00940771.2006.11461531

Modecki, K. L., Minchin, J., Harbaugh, A. G., Guerra, N. G., \& Runions, K. C. (2014). Bullying prevalence across contexts: A meta-analysis measuring cyber and traditional bullying. Journal of Adolescent Health, 55(5), 602-611. https://doi.org/10.1016/j.jadohealth.2014.06.007

Noltemeyer, A. L., \& Bush, K. R. (2013). Adversity and resilience: A synthesis of international research. School Psychology International, 34(5), 474-487. https://doi.org/10.1177/0143034312472758

Perren, S., \& Hornung, R. (2005). Bullying and delinquency in adolescence: Victims' and perpetrators' family and peer relations. Swiss Journal of Psychology, 64(1), 51-64. https://doi.org/10.1024/1421-0185.64.1.51

Peterson, L., \& Rigby, K. (1999). Countering bullying at an Australian secondary school with students as helpers. Journal of adolescence, 22(4), 481-492. https://doi.org/10.1006/jado.1999.0242 
Pouwelse, M., Bolman, C., Lodewijkx, H., \& Spaa, M. (2011). Gender differences and social support: Mediators or moderators between peer victimization and depressive feelings?. Psychology in the Schools, 48(8), 800-814. https://doi.org/10.1002/pits.20589

Rettew, D. C., \& Pawlowski, S. (2016). Bullying. Child and adolescent psychiatric clinics of North America, 25(2), 235-242. https://doi.org/10.1016/j.chc.2015.12.002

Rhebergen, D., Korten, N. C., Penninx, B. W., Stek, M. L., van der Mast, R. C., Voshaar, R. O., \& Comijs, H. C. (2015). Hypothalamic-pituitary-adrenal axis activity in older persons with and without a depressive disorder. Psychoneuroendocrinology, 51, 341-350. https://doi.org/10.1016/j.psyneuen.2014.10.005

Rigby, K., \& Slee, P. T. (1991). Bullying among Australian school children: Reported behavior and attitudes toward victims. The journal of social psychology, 131(5), 615-627. https://doi.org/10.1080/00224545.1991.9924646

Sainio, M., Veenstra, R., Huitsing, G., \& Salmivalli, C. (2011). Victims and their defenders: A dyadic approach. International journal of behavioral development, 35(2), 144-151. https://doi.org/10.1177/0165025410378068

Salmivalli, C., Kaukiainen, A., Kaistaniemi, L., \& Lagerspetz, K. M. (1999). Self-evaluated self-esteem, peer-evaluated self-esteem, and defensive egotism as predictors of adolescents' participation in bullying situations. Personality and Social Psychology Bulletin, 25(10), 1268-1278. https://doi.org/10.1177/0146167299258008

Setoyama, Y., Yamazaki, Y., \& Namayama, K. (2011). Benefits of peer support in online Japanese breast cancer communities: differences between lurkers and posters. Journal of medical Internet research, 13(4). https://doi.org/10.2196/jmir.1696

Smith, P. K., Talamelli, L., Cowie, H., Naylor, P., \& Chauhan, P. (2004). Profiles of non - victims, escaped victims, continuing victims and new victims of school bullying. British journal of educational psychology, 74(4), 565-581. https://doi.org/10.1348/0007099042376427

Sobel, M. E. (1987). Direct and indirect effects in linear structural equation models. Sociological Methods \& Research, 16(1), 155-176. https://doi.org/10.1177/0049124187016001006

Takizawa, R., Maughan, B., \& Arseneault, L. (2014). Adult health outcomes of childhood bullying victimization: evidence from a five-decade longitudinal British birth cohort. American journal of psychiatry, 171(7), 777-784. https://doi.org/10.1176/appi.ajp.2014.13101401

Uba, I., Yaacob, S. N., \& Juhari, R. (2010). Bullying and its' relationship with Depression among Teenagers. Journal of Psychology, 1(1), 15-22. https://doi.org/10.1080/09764224.2010.11885441

Vaughan, C. A., Foshee, V. A., \& Ennett, S. T. (2010). Protective effects of maternal and peer support on depressive symptoms during adolescence. Journal of abnormal child psychology, 38(2), 261-272. https://doi.org/10.1007/s10802-009-9362-9

Wang, J., Iannotti, R. J., \& Nansel, T. R. (2009). School bullying among adolescents in the United States: Physical, verbal, relational, and cyber. Journal of Adolescent health,45(4), 368-375. https://doi.org/10.1016/j.jadohealth.2009.03.021

\section{Copyrights}

Copyright for this article is retained by the author(s), with first publication rights granted to the journal.

This is an open-access article distributed under the terms and conditions of the Creative Commons Attribution license (http://creativecommons.org/licenses/by/4.0/). 